\title{
Health Careers Recruitment Activities in the Islands
}

\author{
Kelley Withy, Kehau Bishaw, and Marilyn Link \\ University of Hawaii, John A. Burns School of Medicine
}

\begin{abstract}
To determine the feasibility of a resident physician-based, culturally appropriate method of The Hawaii/Pacific Basin Area Health Education Center (HI/PB AHEC) has a goal of increasing the proportion of the health professions workforce that comes from underrepresented groups, particularly native Hawaiians. This paper discuss some of the HI/PB AHEC partnership and recruitment efforts.
\end{abstract}

(c) 2005 Californian Journal of Health Promotion. All rights reserved.

Keywords: underrepresented Hawaiians, career development, Hawaii/Pacific Basin Area Health Education Center

The state of Hawaii is unique in that it is geographically isolated from the rest of America, has no ethnic majority, and is home to a robust, yet underserved indigenous population. Although over $20 \%$ of the population is native Hawaiian, the indigenous people of Hawaii are underrepresented in all professional careers, particularly the sciences. In fact, when last assessed, native Hawaiians composed only 4\% of the physicians in the state (Else, Palofox, \& Little, 1998).

The Hawaii/Pacific Basin Area Health Education Center (HI/PB AHEC) has a goal of increasing the proportion of the health professions workforce that comes from underrepresented groups, particularly native Hawaiians. For this reason, broad partnerships and culturally competent activities are being utilized for students and families, to increase health and science knowledge, as well as subsequent interest in science careers. Activities include collaboration with Bishop Museum, the premier museum of Hawaiian history and science, to provide outreach activities to 10 rural communities, and partnership with the Hawaii Department of Education and local schools to educate more than 2,000 students a year in 40 schools about health science careers, providing teacher training in health education for 200 teachers a year through collaboration with the University of Hawaii College of Education.
The challenge for the recruitment personnel is to expose and inform the young people (grades K12) of Hawaii about the options in health professions, the options in education and to affirm that they can achieve the goals they choose for themselves.

Once they were invited to schools (a challenge in itself), the recruiters made presentations in classrooms that complimented and enhanced existing curriculum and kept the students interested and engaged. The recruiters accomplished this by incorporating icebreakers, interactive activities, video, role-play and lecture to expose and inform students of their options in health careers and post-secondary education. Honest comments from the students were valuable in improving the presentations. Students in rural areas are tactile and that was important to create an environment of learning that was fun and participatory.

Through partnership with the Bishop Museum a traveling science show for parents, students, and the community at large was developed and is being utilized in 10 of the most rural areas of the state to increase science literacy and interest in health and health careers, as well as family acceptance of and interest in their students pursuing health science careers. These visits, paired with in-school recruitment visits, and expanded teacher training, have made an impact on health science career interest in rural areas. 
Fueled by a passion for young people and the challenge of informing the diversity of Hawaii schools and students about the options in health careers, the recruiters for the Hawai'i/Pacific Basin Area Health Education were able to contact over 2,000 students a year. Of the 2,348 students contacted in 2004, less than $50 \%$ were aware of health professions other than medicine and nursing. Of the students contacted, 848 students returned questionnaires, of which 83.5\% expressed interest in at least one health related profession, $37.8 \%$ expressed interest in more than one health profession, $16.4 \%$ had no interest in health careers, and $48 \%$ requested additional information on one or more health science career.

Therefore, a program for visitations to Health Science Programs (HSP) at the University of Hawaii-Manoa (UHM) was the next step in recruitment. The AHEC recruiters partnered with the Departments of Medical Technology and Speech Pathology and Audiology, the Health Careers Opportunity Program, and the Schools of Social Work, and partnered to host students on a campus visit of University of Hawaii at Manoa. This subsequently led to the creation of regular 'Options in Health Professions” (OHP) visits. Joined by the School of Nursing - 'Ike Ao Pono program and John A. Burns School of Medicine, the OHP hosted the first group of 75 students from Wai'anae High School in Fall 2003. Since then the OHP partners have hosted 600 students from all the islands, as it enjoys its second year of campus visits.

Taking this a step further, the "Health Occupations Summer Institute” (HOSI) was born to provide hands-on experiences with health careers other than physician and nursing. The Hawaii State Department of Education, Kapi'olani Community College, University of Hawaii at Manoa, and AHEC, partnered to provide a three-day program modeled after the Health Career Opportunity Program's four-week summer program. Summer 2003 found twentyfour HSCP students participating in information packed, hands-on experience at the community college health science programs, and the Departments of Medical Technology and Speech Pathology and Audiology.

As the HI/PB AHEC recruitment team continues to work together with the Health Science Partners in creating recruitment efforts to provide Hawaii's young people with the education, experiences, and support they need to achieve their goals, it is our hope that we have done an effective job in equipping Hawaii's youth to become the future health care professionals in their communities. We will visit any school in Hawaii that contacts us and we hope to continue and expand collaborative activities to even more schools that the 40 currently serviced. Schools that would like a visit should contact us through http://www.ahec.hawaii.edu.

\section{References}

Else, I., Palafox, N., \& Little, D. (1998). Where are the Native Hawaiian physicians? Pacific Health Dialog, 5(2).

\section{Acknowledments}

This project was supported by Science Education Partnership Award grant, R25-RR17312, from the National Center for Research Resources, National Institutes of Health and Area Health Education Center, and Award grant, U76HP00578, from the Health Resources and Services Administration Bureau of Health Professions. 


\author{
Author Information \\ Kelley Withy, MD* \\ University of Hawaii \\ John A. Burns School of Medicine \\ 651 Ilalo Street, MEB 401J \\ Honolulu HI 96813 \\ E-Mail: withy@hawaii.edu \\ Kehau Bishaw \\ Marilyn Link \\ University of Hawaii \\ John A. Burns School of Medicine \\ 651 Ilalo Street, MEB 401J \\ Honolulu HI 96813 \\ * corresponding author
}

